\title{
Control Strategy of Thyristors Switched SVCs with High Power Quality
}

\author{
D. I. Panfilov \\ Department of industrial \\ electronics \\ Moscow power engineering \\ institute \\ Moscow, Russia \\ Dmitry.panfilov@inbox.ru
}

\author{
Ahmed E. ElGebaly \\ Electrical power and machines \\ department \\ Faculty of engineering- Tanta \\ university \\ Tanta, Egypt \\ Ahmed.elgebaly@,f- \\ eng.tanta.edu.eg
}

\author{
M. G. Astashev \\ G. M. Krzhizhanovsky power \\ engineering institute \\ (JSC ENIN) \\ Moscow, Russia \\ astashev@eninnet.ru
}

\author{
Alexander N. Rozhkov \\ Department of \\ industrial electronics \\ Moscow power \\ engineering institute \\ Moscow, Russia \\ rozhkovan@eninnet.ru
}

\begin{abstract}
In this paper, new static VAR compensators SVCs schemes for inductive and capacitive reactive power are developed. The provided schemes improve the flexibility and power system quality of SVCs by developing new circuit topologies with new control strategy of the reactive power. New circuit schemes are introduced for thyristors switched reactors TSR and thyristors switched capacitors TSC to design harmonicfree SVC with higher discrete number of reactive power levels. This paper provides the control algorithm and block diagram of the new SVCs schemes. The switching strategies of TSR and TSC are described and implemented. The new scheme of TSC requires special modifications to decrease transient effects and implementation of specific switching strategies to acquire SVC with high power quality indexes.
\end{abstract}

Keywords—static VAR compensators, thyristor switched reactors, thyristor switched capacitors

\section{INTRODUCTION}

Static VAR compensators SVC play an important role in electrical power systems because of their capability to dynamically compensate the reactive power. The SVC fundamentally is made up of inductive reactive power source, such as thyristor-controlled reactor TCR or thyristors switched reactors TSR, and capacitive reactive power source, for instance fixed capacitor FC and thyristors switched capacitors TSC [1]. The advance of SVC has various research trends such as optimization of the device rating and the place of installation in the power network [2], improvement of power electronics structure in the schemes [3,4,5] and development of SVC control system structure and operation [6]. TSR is considered as a solution to eliminate high order harmonics which are commonly produced in SVC based on TCR scheme. The new TSR topologies have flexible performance than the simple equal parallel branches or binary TSR schemes [7]. The existed TSC has one of the following topologies: equal rating parallel

The study was performed at Stock Company G. M. Krzhizhanovsky Power Engineering Institute within the framework of the project

"Development of a controlled source of reactive power with the absence of the higher-order harmonics currents during the regulation of the electrical energy and with the improved technical and economicl indicators on the basis of the domestic component base of power electronics for automatic control of the voltage and the power flows in the electric power distribution networks of 6 $110 \mathrm{kV}$ (RFMEFI57917X0140)" with the financial support of the Ministry of Education and Science of the Russian Federation

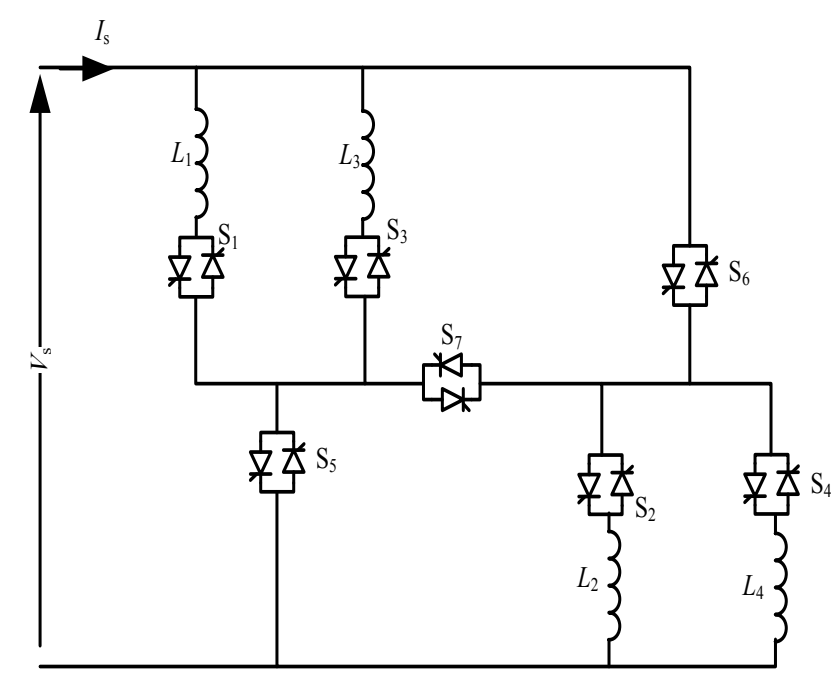

Fig. 1. TSR with 25 power steps

TSC branches and binary TSC [8].

In the paper, new developed circuit topologies for both of TSR and TSC are developed with essential idea of increasing the number of steps of reactive power compensation with the same number of passive elements (reactors and capacitors). This paper demonstrates the principle of the new schemes operation. The characteristics of the new schemes that relates between the required and developed reactive power is provided in this paper. Furthermore, the control strategy and construction of the new developed schemes are clarified. The modification of TSC operation during transients is implemented with special algorithm and circuitry.

\section{CIRCUITS TOPOLOGIES OF IMPROVED TSC AND TSR}

TSR and TSC new schemes are developed to control the reactive power with zero harmonic content but with discrete manner. The earlier schemes of TSR control the developed reactive power by varying the equivalent inductance of the parallel connected reactors. The developed schemes control the reactive power not only by changing the parallel connected branches but also by series connection of passive elements [9]. Fig. 1 illustrates a new circuit scheme for TSR which consists 
four reactors and seven back-to-back thyristor switches. This scheme allows to obtain 25 different equivalent inductances; thus, it produces 25 reactive power steps. It can become evident that with additional three switches, the number of steps are increased from 16 steps in binary TSR to 25 steps in the new scheme [10]. TABLE I shows the different equivalent inductances and the states of operation of the switches where + means series connection and // means parallel connection of reactors. The total apparent power of reactors in the new scheme equals the total apparent power of the reactor used in conventional TCR and binary TSR [10]. With the same manner, the number of reactors may be more than four, but the number of switches will be more than the number of reactor by 3. These three switches are $S_{5}, S_{6}$ and $S_{7}$ in Fig. 1 .

TABLE I. THE EQUIVALENT INDUCT ANCE OBTAINED BY NEW TSR WITH FOUR REACTORS AND SEVEN SWITCHES

\begin{tabular}{|c|c|c|c|c|c|c|c|c|}
\hline \multirow[b]{2}{*}{ No. } & \multirow{2}{*}{$\begin{array}{l}\text { Equivalent } \\
\text { inductance }\end{array}$} & \multicolumn{7}{|c|}{ Switches state } \\
\hline & & $\mathrm{S}_{1}$ & $\mathrm{~S}_{2}$ & $\mathrm{~S}_{3}$ & $\mathrm{~S}_{4}$ & $\mathrm{~S}_{5}$ & $\mathrm{~S}_{6}$ & $\mathrm{~S}_{7}$ \\
\hline 1 & 0 & OFF & OFF & OFF & OFF & OFF & OFF & OFF \\
\hline 2 & $L_{1}+L_{2}$ & $\mathrm{ON}$ & $\mathrm{ON}$ & OFF & OFF & OFF & OFF & ON \\
\hline 3 & $L_{2}+L_{3}$ & OFF & $\mathrm{ON}$ & ON & OFF & OFF & OFF & ON \\
\hline 4 & $\left(L_{1} / / L_{3}\right)+L_{2}$ & $\mathrm{ON}$ & $\mathrm{ON}$ & $\mathrm{ON}$ & OFF & OFF & OFF & $\mathrm{ON}$ \\
\hline 5 & $L_{2}$ & OFF & ON & OFF & OFF & OFF & ON & OFF \\
\hline 6 & $L_{1}+L_{4}$ & ON & OFF & OFF & ON & OFF & OFF & $\mathrm{ON}$ \\
\hline 7 & $\left(L_{2} / / L_{4}\right)+L_{1}$ & $\mathrm{ON}$ & $\mathrm{ON}$ & OFF & $\mathrm{ON}$ & OFF & OFF & ON \\
\hline 8 & $L_{3}+L_{4}$ & OFF & OFF & ON & ON & OFF & OFF & $\mathrm{ON}$ \\
\hline 9 & $\left(L_{2} / / L_{4}\right)+L_{3}$ & OFF & ON & ON & $\mathrm{ON}$ & OFF & OFF & $\mathrm{ON}$ \\
\hline 10 & $L_{I}$ & ON & OFF & OFF & OFF & ON & OFF & OFF \\
\hline 11 & $\left(L_{1} / / L_{3}\right)+L_{4}$ & $\mathrm{ON}$ & OFF & ON & $\mathrm{ON}$ & OFF & OFF & $\mathrm{ON}$ \\
\hline 12 & $\left(L_{1} / / L_{3}\right)+\left(L_{2} / / L_{4}\right)$ & ON & $\mathrm{ON}$ & ON & $\mathrm{ON}$ & OFF & OFF & ON \\
\hline 13 & $L_{1} / / L_{2}$ & $\mathrm{ON}$ & $\mathrm{ON}$ & OFF & OFF & $\mathrm{ON}$ & $\mathrm{ON}$ & OFF \\
\hline 14 & $L_{3}$ & OFF & OFF & ON & OFF & ON & OFF & OFF \\
\hline 15 & $L_{4}$ & OFF & OFF & OFF & ON & OFF & ON & OFF \\
\hline 16 & $L_{2} / / L_{3}$ & OFF & ON & ON & OFF & ON & ON & OFF \\
\hline 17 & $L_{2} / / L_{4}$ & OFF & ON & OFF & $\mathrm{ON}$ & OFF & ON & OFF \\
\hline 18 & $L_{1} / / L_{3}$ & ON & OFF & ON & OFF & ON & OFF & OFF \\
\hline 19 & $L_{1} / / L_{4}$ & $\mathrm{ON}$ & OFF & OFF & $\mathrm{ON}$ & ON & $\mathrm{ON}$ & OFF \\
\hline 20 & $L_{1} / / L_{2} / / L_{3}$ & $\mathrm{ON}$ & ON & ON & OFF & ON & $\mathrm{ON}$ & OFF \\
\hline 21 & $L_{1} / / L_{4} / / L_{2}$ & ON & ON & OFF & $\mathrm{ON}$ & ON & ON & OFF \\
\hline 22 & $L_{3} / / L_{4}$ & OFF & OFF & ON & $\mathrm{ON}$ & ON & $\mathrm{ON}$ & OFF \\
\hline 23 & $L_{3} / / L_{4} / / L_{2}$ & OFF & $\mathrm{ON}$ & ON & ON & ON & ON & OFF \\
\hline 24 & $\overline{L_{1} / / L_{4} / / L_{3}}$ & ON & OFF & ON & ON & ON & OFF & OFF \\
\hline 25 & $L_{1} / / L_{2} / / L_{3} / / L_{4}$ & $\mathrm{ON}$ & $\mathrm{ON}$ & ON & ON & ON & ON & OFF \\
\hline
\end{tabular}

Fig. 2 demonstrates the new scheme of TSC which contains four capacitors and seven switches. This topology can produce 25 steps of operation such as that of the new TSR in Fig. 1. This scheme is better than binary TSC that contains four branches because the new topology provides 25 steps instead of 16 steps which can produced by binary TSC. Although the topologies of TSR and TSC have the same principle of operation by varying the developed reactive power by changing the equivalent reactance, the method of control of each scheme is different $[11,12]$ as will explained in section IV.

\section{Characteristics optimization OF THE DEVELOPED TSC AND TSR TOPOLOGIES}

The characteristic of the SVC system is the relation between the required reactive power as a reference from the control system and the actual produced reactive power from SVC. The characteristics of the new TSR or TSC schemes have discrete form. Consequently, it is very vital to adjust the SVC characteristics to be most near to the continuous characteristic

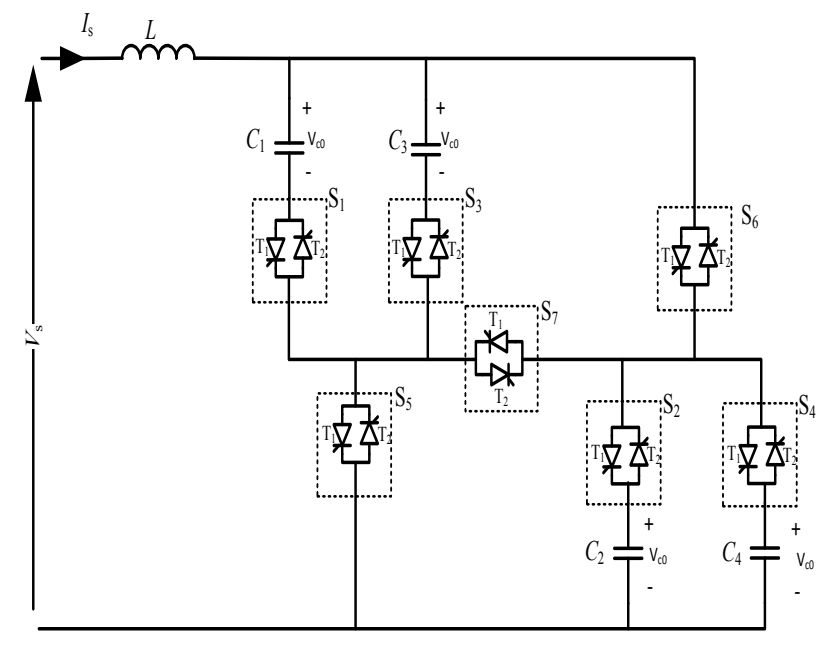

Fig. 2. TSC with 25 power steps

of SVC with TCR. Optimization technique can determine the parameters of each of the new developed schemes to obtain the smoothest variation in the produced reactive power [3]. In this section, the optimization technique is applied for TSR and with the same way it can be applied for TSC [3]. By assuming that, each equivalent inductance $L_{\mathrm{x}}(n)$ produces the inductive reactive power $Q_{\mathrm{d}}$ :

$$
Q_{d}(n)=\frac{V^{2}}{\omega L_{x}(n)}
$$

In the case of the capacitive reactive power, each equivalent capacitance $C_{\mathrm{x}}(n)$ produces capacitive reactive power according the following equation $Q_{d}(n)=V^{2} \omega C_{x}(n)$, where $n$ is the number of the equivalent circuits which depend on the switches states in Fig. 2. An objective function should be applied to optimize the distribution of the produced reactive power. This objective function O.F.D designates the difference between two consecutive developed reactive power $\left(Q_{d}(n)\right.$, $\left.Q_{d}(n+1)\right)$, while this difference shouldn't exceed certain determined value $\Delta Q$.

$$
\text { O.F.D }=\sum_{n=1}^{m-1}\left(Q_{d}(n+1)-Q_{d}(n)\right)-\Delta Q
$$

where $m$ is the total number of steps obtained by the developed scheme.

This objective function is used for both of new TSR and TSC schemes. Optimization technique that depends on genetic algorithm GA is used to solve this objective function. The constraint for the variables is the ratio between the maximum and the minimum variables (maximum and minimum inductance or capacitance of passive elements) doesn't exceed 8. So, the parameters of TSR and TSC can be determined as a function of rated inductance $L_{\mathrm{eq}}$ and rated capacitance $C_{\mathrm{eq}}$ correspondingly. The values of inductances to obtain the finest solution are as the following: $L_{1}=5.1 L_{\mathrm{eq}}, L_{2}=10.8 L_{\mathrm{eq}}, L_{3}=3$ $L_{\mathrm{eq}}, L_{4}=2.6 L_{\mathrm{eq}}$. While the value of capacitance for TSC optimal design $C_{1}=0.2 C_{\mathrm{eq}}, C_{2}=0.0998 C_{\mathrm{eq}}, C_{3}=0.3248 C_{\mathrm{eq}}$, 


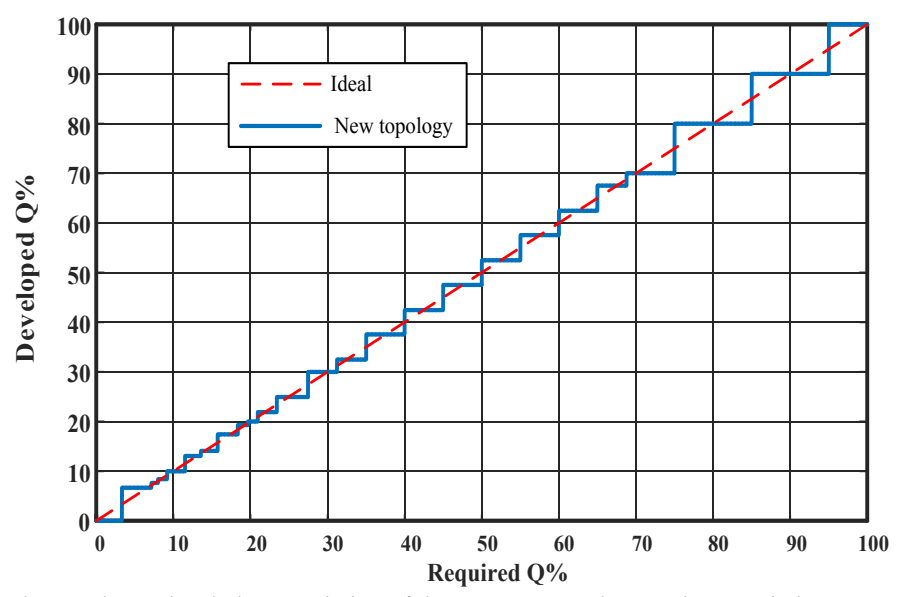

Fig. 3. The optimal characteristics of the new TSR and TSC characteristics

$C_{4}=0.3754 C_{\text {eq }}$. The predetermined parameters offer the characteristic for each of TSR or TSC as demonstrated in Fig. 3. This characteristic links between the required reactive power from the scheme and the discrete produced reactive power. It can be noted that this characteristic may be inductive or capacitive according to the type of the scheme. To get certain required reactive power, certain step of 25 steps should be realized consistent with its percentage. The grouping between the two new TSC and TSR schemes provides more smooth variation in the group characteristic.

\section{AlgORITHMS OF THYRISTORS CONTROLLING IN NEW SVC SCHEMES}

Fig. 4 demonstrates the general block diagram of SVC with discrete TSR and TSC. The required susceptance $B$ (the required reactive power) is converted to required inductive susceptance and required capacitive susceptance [4]. The required susceptance $B$ is converted by the control system to specified step according to the characteristics of TSR or TSC. This control system is essential for the discrete control SVC schemes and has the required blocks to diminish the effect of the discrete characteristics [4].
The inductive reactive power control is occurred because of the changing of the inductance value consistent with the certain step as in Fig. 5. The varying of inductance value is simple because it should be occurred at zero crossing of current. For inductive current, the current zero crossing occurs at voltage phase angles of $90^{\circ}$ and $270^{\circ}$ i.e. at the moment of maximum instantaneous voltage. Therefore, the maximum time delay in this case equals half cycle of the fundamental frequency. Fig. 6 illustrates the block diagram of the TSR control system which contains three main components; the first is the block responsible for the synchronization between the TSR and the power grid; the second is the block responsible for the determination of the required susceptance and therefore the required operated switches; the third block is the firing circuit of thyristors. Fig. 7 shows the waveforms of TSR current and voltage throughout the changing from one step to another. If new step is required by the control system, the implementation of the new step happens only at the zero-crossing of the current or the maximum amplitude of instantaneous voltage.

Conversely, the capacitive reactive power control of TSR is more complicated. There is no opportunity to switch on a switch in series with sinusoidal power supply and capacitor because there is a need to avoid the sudden change of voltage on the capacitor which leads to excessive level of current which may lead to the damage of the switch and the capacitor. In some cases, when the firing angle of the switch occurs at zero crossing of voltage, the high value of current change $d i / d t$ is very hazard for the switch. Consequently, connection of small damping inductors in series with capacitor will reduce the high values of current or its rate of change [11].

For the new scheme of TSC, it is preferred to install a reactor $L$ in series with power supply as in Fig. 2 . This reactor plays vital role not only for switching on the capacitors with lower transients but also for preparing the capacitors for the next step. The developed topology depends on the series connection and parallel connection. Nonetheless, the connection of capacitors in series needs the discharging of all capacitors to prevent residual DC charge on capacitors during producing of capacitive current. Consequently, the control

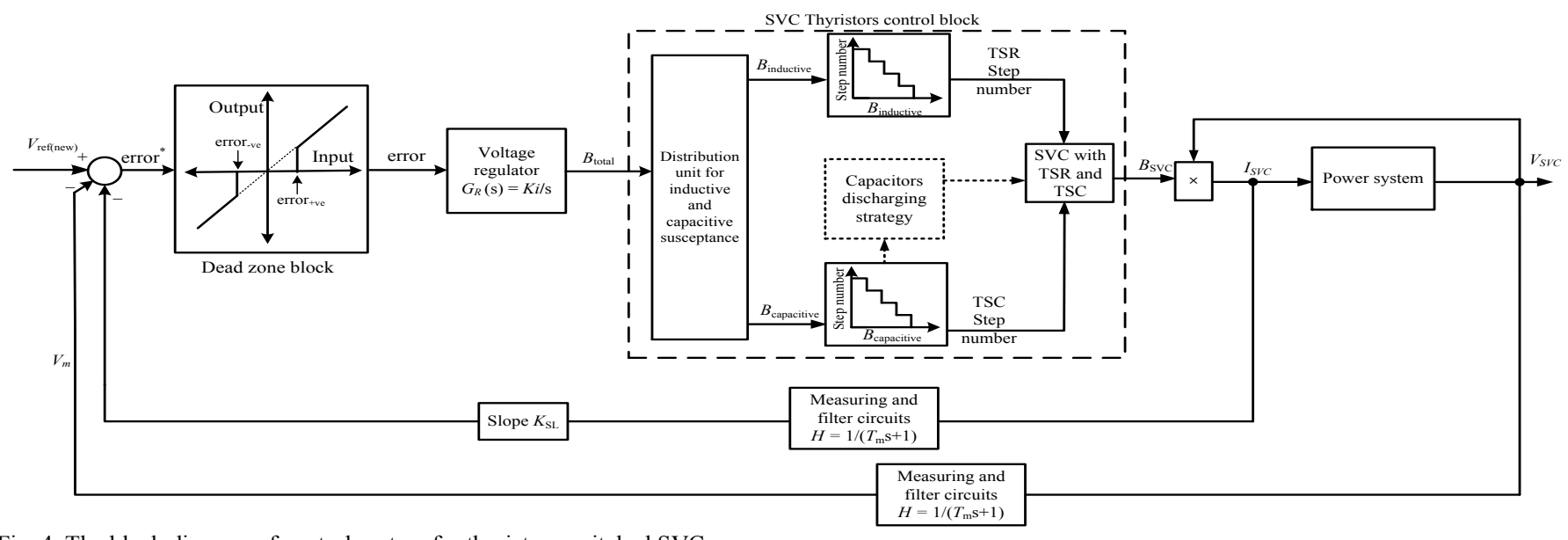

Fig. 4. The block diagram of control system for thyristors switched SVC 


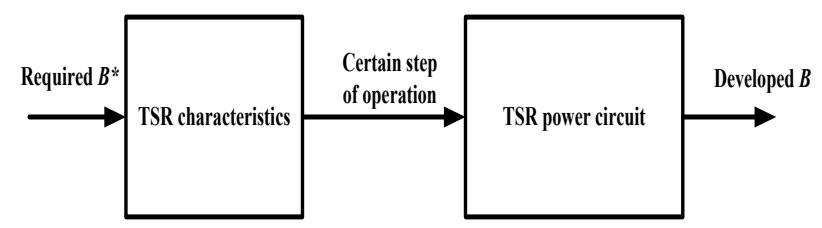

Fig. 5. Flow chart for controlling thyristors switched reactors

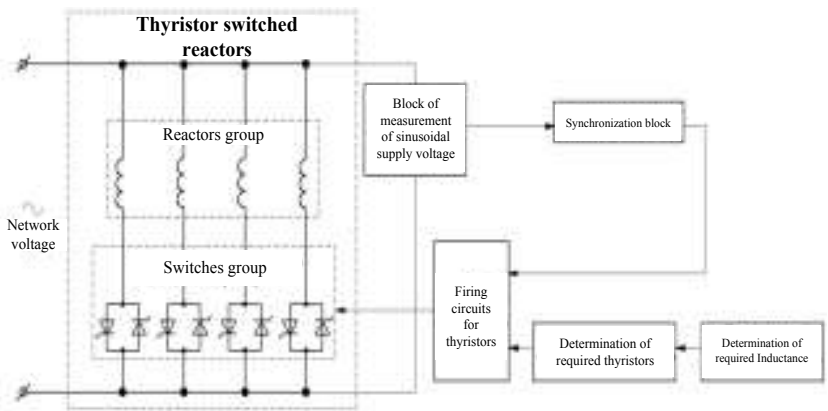

Fig. 6. Block diagram of TSR control system

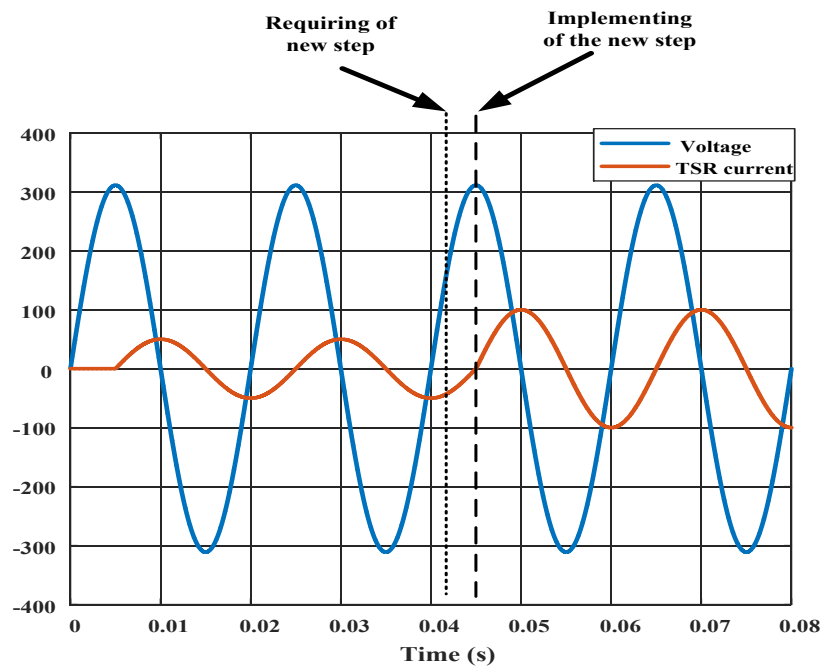

Fig. 7. TSR voltage and current waveforms during transition from one step to another

algorithm of TSC should contain the discharging process earlier than the starting of the new step of operation. After the capacitors discharging, the new connection of the capacitors starts at the next voltage zero crossing. Fig. 8 illustrates the flow chart of the control algorithm of TSC to start new step of operation. Consistent with this algorithm, if there is requirement of new value of susceptance $B$, the discharging process should be activated before the implementation of new value of $B$. Fig. 9 demonstrates the detailed block diagram of the TSC control system which contains the blocks required for the changing of the required susceptance and the discharging of the capacitors. Fig. 10 (a) demonstrates the waveforms of the supply voltage and the current of the TSC in the transition between two steps where the TSC current equals zero during the discharging period except the impulse current due to capacitor discharge. Fig. 10 (b) shows the voltage of certain

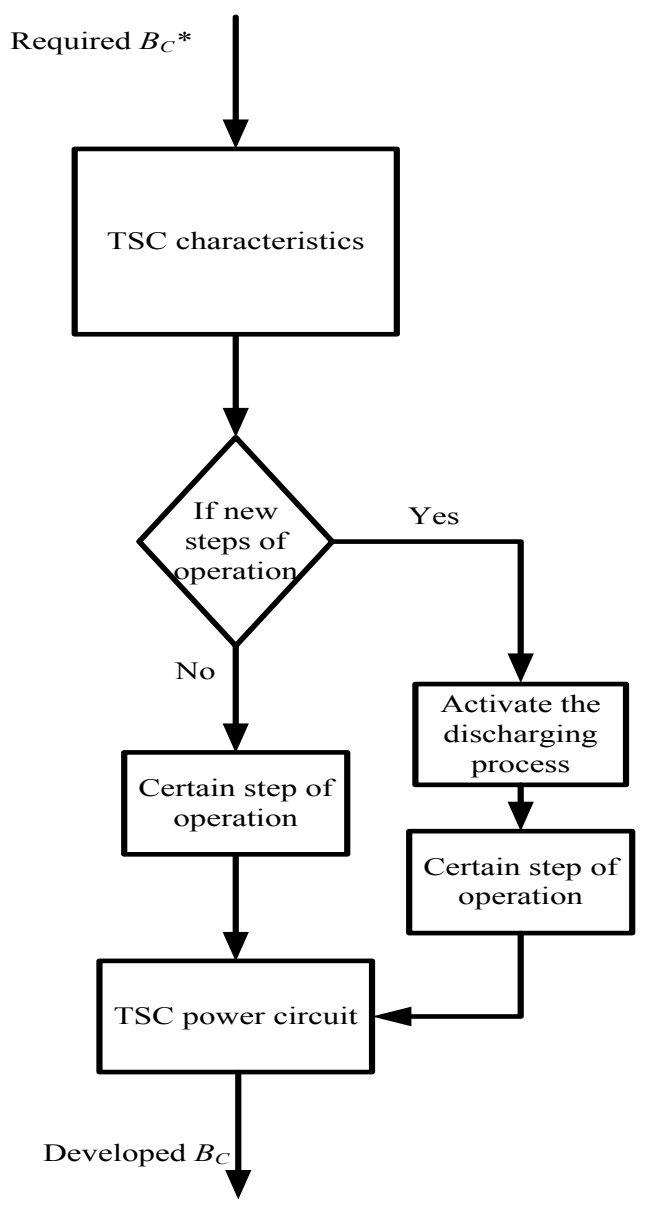

Fig. 8. Flow chart of algorithms for controlling thyristors switched capacitor in the transition process the voltage is kept constant till the moment to discharge it to zero voltage.

The special discharging process for capacitors is applied within only one quarter of the fundamental period to keep the fast response of the overall system. If the capacitors are charged with positive or negative charge from the previous state of operation, this energy could be regenerated to the power supply depending on the reactor $L$. Therefore, the inductance $L$ of installed reactor and the equivalent capacitance $C_{\text {eq }}$ should provide resonance frequency higher than the fundamental frequency $\omega_{0}$ to end the discharging process in very short time. The resonance frequency recommended in this paper equals 24 times the fundamental frequency. So, the value inductance $L$ can be determined with maximum capacitance $C_{\text {eq }}$ and resonance frequency of $24 \omega_{0}$.

$$
L=\frac{1}{\left(24 \omega_{0}\right)^{2} C_{e q}}
$$

For delta connected TSC $200 \mathrm{kVAR}, 400 \mathrm{~V}$-line voltage, the value of $C_{\text {eq }}$ equals $1315 \mu \mathrm{F}$ and the value of inductance equals $13.2 \mu \mathrm{H}$. The control algorithm for the discharging can be explained according to the following example: assume all capacitors have remaining voltages $V_{\mathrm{c} 0}$ illustrated in Fig. 2 which equals $220 \sqrt{2} \mathrm{~V}$. The goal is the regeneration of this 


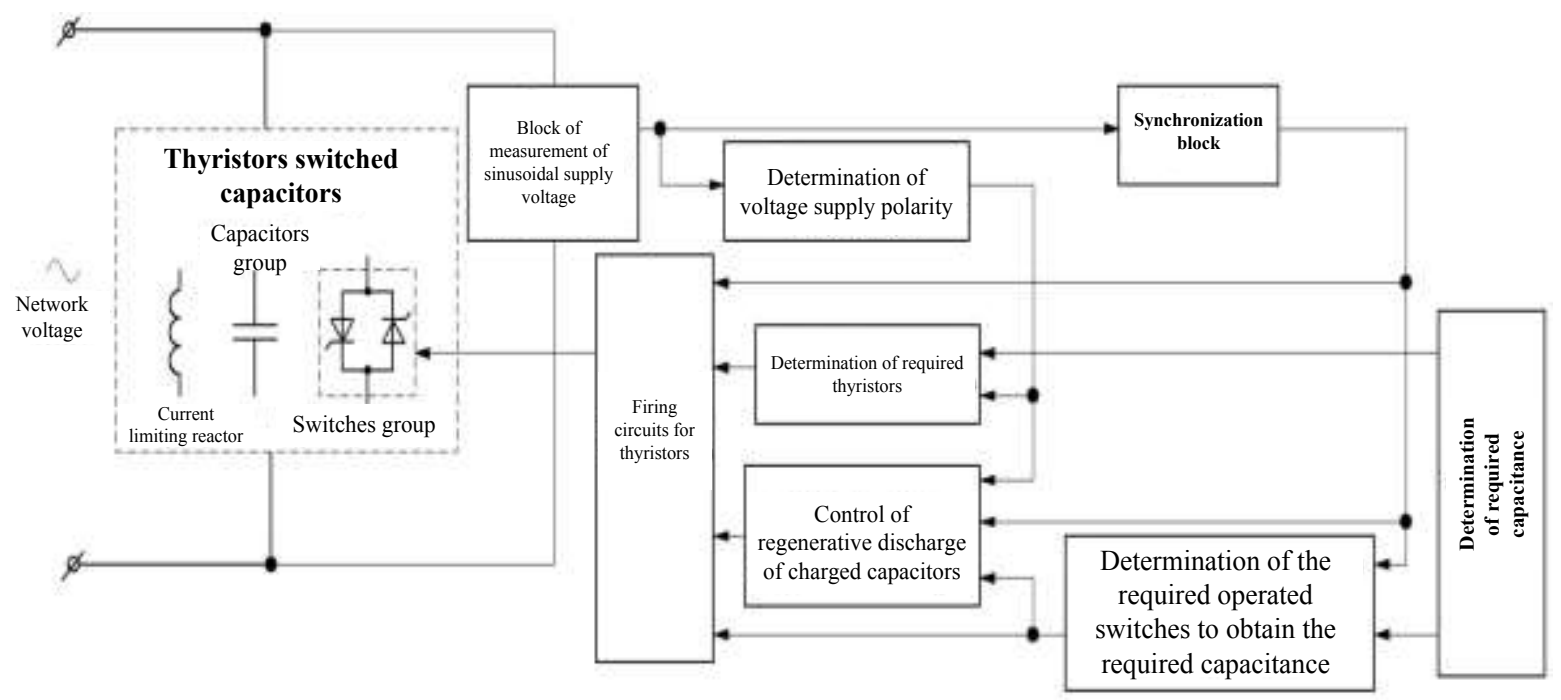

Fig. 9. Block diagram of new topology of TSC control system

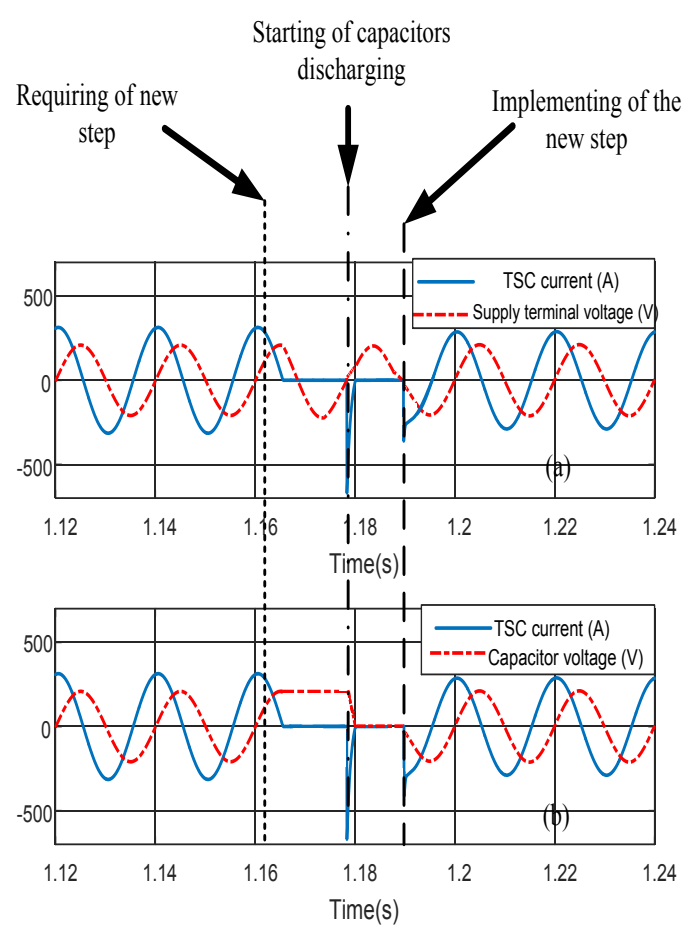

Fig. 10. The waveform of the applied voltage on TSC and its current and a voltage on one capacitor

stored energy to the supply to reduce the capacitor voltage to zero level. The starting of discharging happens when the waveform of voltage passes through zero to the positive values as in Fig. 11 (a) and the thyristors $\mathrm{T}_{2}$ for all switches are fired in this moment. Fig. 12 illustrates the flow of current during discharging of capacitors where all switches except $\mathrm{S}_{7}$ operate in the direction enables to discharge the capacitors. In this moment, the voltage of capacitors is more than the instant value of supply voltage; so, all capacitors produce currents passes through reactor $L$ and thyristors $\mathrm{T}_{2}$ in all switches except $\mathrm{S}_{7}$. This current has negative sign with respect to the power supply as in Fig. 11 (b). At the moment when the capacitors voltage reaches zero Fig. 11 (c) $(0.35 \mu \mathrm{s})$ the thyristors $T_{2}$ in
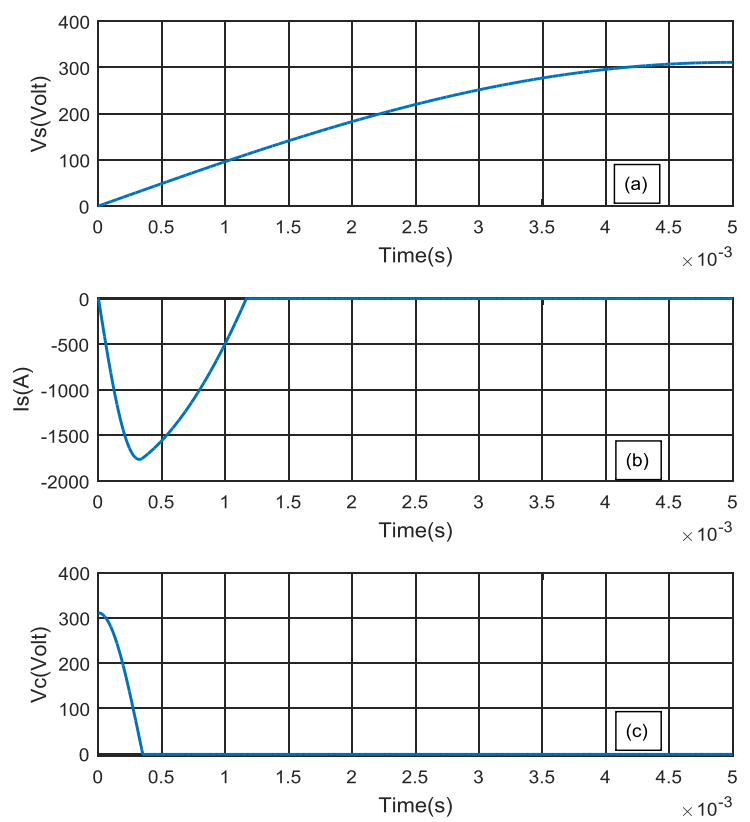

Fig. 11. Discharging process for capacitor of TSC with regeneration of energy (a) the supply voltage, (b) the supply current and (c) the capacitors voltage

the switches $\mathrm{S}_{1}, \mathrm{~S}_{2}, \mathrm{~S}_{3}$ and $\mathrm{S}_{4}$ are changed to off state (open circuit). But, the inductor current continuous passing in the same direction through thyristors $T_{2}$ in switches $S_{5}, S_{6}$ and $S_{7}$. The positive voltage of the supply forces the current to decay to zero as in Fig. 11 (b) in the period 0.35 to $1.1 \mu$ s. Then the capacitors are ready to the next connection through the power supply at the next voltage zero crossing. With the same strategy the discharging of capacitors can be applied if the capacitors are charged with negative sign.

\section{CONCLUSION}

This paper has provided new topologies of thyristors switched SVC which control the reactive power with zero 


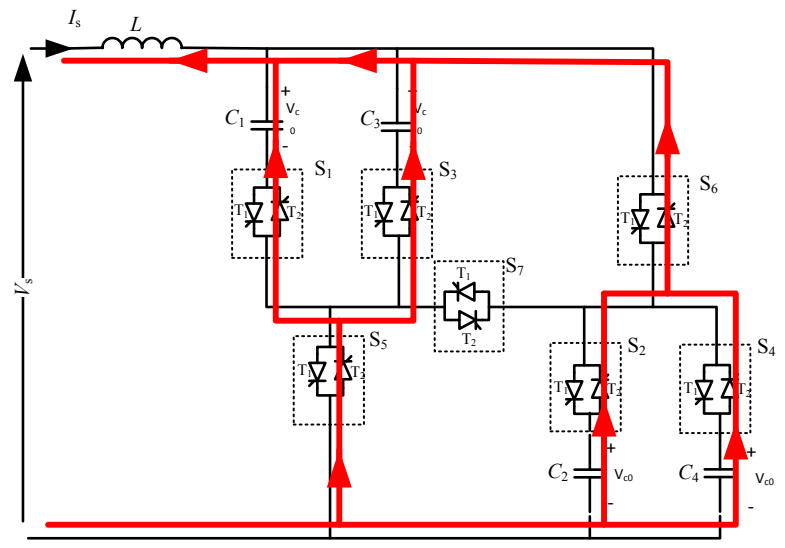

Fig. 12. Discharging path for positively charged capacitors of TSC

harmonic content. The power circuitries for inductive and capacitive schemes of the new SVC are introduced. The principle of operation of new SVC has been explained to illustrate the basics of the control system algorithm. The block diagram of the control system of the new SVC system has been introduced with some modifications than the conventional SVC. The control algorithm for TSR of the new SVC schemes has been explained. The control algorithm for TSC is developed including the switching strategy required for the discharging of capacitors.

\section{ACKNOWLEDGMENT}

The study was performed at Stock Company G. M. Krzhizhanovsky Power Engineering Institute within the framework of the project " Development of a controlled source of reactive power with the absence of the higher-order harmonics currents during the regulation of the electrical energy and with the improved technical and economical indicators on the basis of the domestic component base of power electronics for automatic control of the voltage and the power flows in the electric power distribution networks of 6$110 \mathrm{kV}$ (RFMEFI57917X0140)" with the financial support of the Ministry of Education and Science of the Russian Federation.

\section{REFERENCES}

[1] L. Gyugyi, "Power electronics in electric utilities: static VAR compensators", Proceedings of the IEEE, Vol: 76, Issue: 4, April 1988

[2] Sharma, P. R. Kumar, A. Kumar, N. Optimal Location for Shunt Connected FACTS Devices in a Series Compensated Long Transmission Line. // Turk J Elec Engin. 15, 3(2007), pp. 321-328.

[3] D. I. Panfilov, A. E. ElGebaly, M. G. Astashev and Alexander N. Rozhkov, "New Approach for Thyristors Switched Capacitors Design for Static VAR Compensator Systems" 19th International Conference of Young Specialists on Micro/Nanotechnologies and Electron Devices June 29 - July 3, 2018

[4] D. I. Panfilov, A. E. ElGebaly and M. G. Astashev, "Design and Optimization of New Thyristors Controlled Reactors with Zero Harmonic Content", 18th International Conference of Young Specialists on Micro/Nanotechnologies and Electron Devices June 29 - July 3, 2017

[5] D. I. Panfilov, A. E. ElGebaly and M. G. Astashev, "Design and evaluation of control system for static VAR compensators with thyristors switched reactors" IEEE 58th International Scientific Conference on Power and Electrical Engineering of Riga Technical University (RTUCON), Riga, Latvia, 12-13 October 2017

[6] D.I. Panfilov, A. E. ElGebaly, "Modified Thyristor Controlled Reactors for Static VAR Compensators" 2016 IEEE $6^{\text {th }}$ International Conference on Power and Energy (PECON 2016), Melaka, Malaysia, November 2016

[7] D. I. Panfilov, A. E. ElGebaly and M. G. Astashev, "Topologies of thyristor controlled reactor with reduced current harmonic content for static var compensators" 17th EEEIC concerence, Milan, Italy, 6-9 June 2017

[8] A. E. Elgebaly, D. I. Panfilov and M. G. Astashev "Comparative Evaluation of Binary and Conventional Static VAR Compensators" Mechanics, Materials Science \& Engineering journal (mmse), vol. 17, 2018

[9] D. I. Panfilov, A. E. Elgebaly and M. G. Astashev, "Design and Assessment of Static VAR Compensator on Railways Power Grid Operation under Normal and Contingencies Conditions", 16th EEEIC conference, Florence, Italy, 7-10 June 2016

[10] D. I. Panfilov, A. E. ElGebaly and M. G. Astashev, "Thyristors Controlled Reactors for Reactive Power Control with Zero Harmonics Content", 17th IEEE International Conference on Smart Technologies IEEE EUROCON 2017, Ohrid, Macedonia, 6 - 8 July 2017

[11] N. Garcia ; A. Medina "Fast periodic steady state solution of systems containing thyristor switched capacitors", 2000 power engineering society summer meeting Seattle, Washington USA, 16 - 20 July 2000

[12] A.N. Vasconcelos, et.al, "Detailed Modeling of An Actual Static Var Compensator for Electromagnetic Transient Studies", IEEE Transactions on Power Systems, Vol. 7, No. 1, February 1992. 